
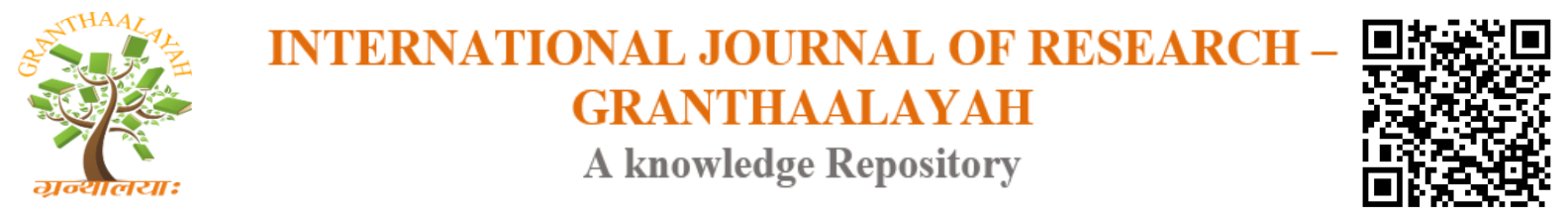

Management

\title{
THE ALGERIAN FAMILY BUSINESS AND THE UPGRADING PROGRAMS: A QUALITATIVE APPROACH
}

\author{
Lyes OUABDESSELAM ${ }^{* 1}$, Fethi NOUI ${ }^{2}$ \\ ${ }^{* 1}$ Board of Directors, SPA CRAPC EXPERTISE (Commercial Subsidiary of the Center for \\ Scientific and Technical Research / CRAPC), Algeria \\ ${ }^{2}$ Department of Economic Sciences, University of Algiers, Algeria
}

DOI: https://doi.org/10.29121/granthaalayah.v5.i4.2017.1816

\begin{abstract}
In order to support SMEs in their modernization and competitiveness efforts, the authorities have put in place a support strategy through the various support programs led by the Ministry of Industry and Mines (ex- Ministry of Small and Medium-Sized Enterprises and Crafts) in collaboration with the European Commission, such as the Euro-SME Development Program (EDPME). In this context, this work was carried out in order to help clarify one of the upgrading programs carried out in Algeria. The aim is to discover the real situation of one of the family SMEs in Algeria. In this study, we adopted a qualitative approach focusing on the often intuitive management mode of the company. This study made it possible to make an inventory and a strategic diagnosis of the targeted family business and tries to shed light on the obstacles to the achievement of the overall objectives of the upgrading operations. This study made it possible to carry out an ex-post evaluation and reveal a set of obstacles to the development of Algerian family-owned SMEs. This publication aims to contribute to the capitalization of the experience of the upgrading programs in Algeria.
\end{abstract}

Keywords: Family Business; Diagnosis; Program; Upgrading; Algeria.

Cite This Article: Lyes OUABDESSELAM, and Fethi NOUI. (2017). "THE ALGERIAN FAMILY BUSINESS AND THE UPGRADING PROGRAMS: A QUALITATIVE APPROACH." International Journal of Research - Granthaalayah, 5(4), 238-245. https://doi.org/10.29121/granthaalayah.v5.i4.2017.1816.

\section{Introduction}

The Algerian economy experienced a historic change in the early 1990s. This economic change is due to political change. After decades of managed administration characterized by a lack of international competitiveness and an orientation towards public enterprises. Private sector companies in Algeria have been severely disadvantaged [1]. With the opening of the market; The development of small and medium-sized enterprises (SMEs) in Algeria has grown 
considerably, encouraged by public incentives in terms of institutional framework, public support, regulation and upgrading [2]. The public authorities have therefore set up an accompanying strategy to help companies in their modernization and competitiveness efforts through various programs, in particular the Algerian SME / SMI support program or the SME upgrading program. Despite the current oil shock, the state has made progress in improving the business climate and is working on a long-term strategy to transform the country's growth model in order to promote private sector activity and diversify the economy. Economy is at the center of its strategy [3]. In this context, our work tries to establish an inventory of a family business which has benefited from the various measures to promote and support SMEs Than the upgrade program). Its objective is to make an ex-post evaluation of the programs and to disclose the problems encountered by SMEs. The aim is not to evaluate policies to support and assist SMEs but to discover the current and actual situation of SMEs in Algeria.

\section{Overview of SMEs in Algeria}

SMEs are a central player in any economy [4]. In the current economic context, marked by a movement of globalization and fierce competition at all levels and following the sudden oil shock; It is now established that SMEs are an indispensable element in the process of economic development in Algeria. They energize the regions, create wealth and many jobs [5]. This is a key factor in promoting non-hydrocarbon exports [6]. SMEs offer less complex managerial constraints, more flexible production processes and greater adaptability to different market contexts [5]. In Algeria, the constraints of the centralized economy have given way to the constraints of the market economy where competition is at the international level. The agreements signed between Algeria and the European Union and the preparations for its accession to the WTO have created an unprecedented awareness of the factors of competitiveness and performance of companies. Deep changes have had to be adopted [5]. A number of government efforts have been made to this end, including the business support and upgrading programs that have been adopted with particular interest to SMEs. To this end, Algerian SMEs decided to take part in the framework of the "Program to support the development of SMEs in Algeria" (MEDA / EU Program). Notably the sausage companies [2]. In 2009, for example; According to the figures published by the Ministry of Industry, 4,698 enterprises have been delisted, compared to 17,163 enterprises created. A sector-by-sector analysis reveals a high concentration of private SMEs in services (45.98\% of the population) including transport and telecommunications, trade, hotels and restaurants, business services, Services provided to households, financial institutions, real estate affairs, and community services [7] In the first half of 2016, 12,650 companies ceased operations (private SMEs), compared to $1,784,214$ SMEs created. We note that at the end of the first half of 2016, SMEs amounted to $1,014,075$ entities, nearly $57 \%$ of which are legal entities, 438 of which are public companies, the remainder of which are natural persons $(43 \%)$, of which $20 \%$ are self-employed and 23\% [8]. The number of public SMEs has decreased considerably in the number of public SMEs, and earlier research has led to a decline in the number of public SMEs with two contradictory effects: on the one hand, the restructuring of large public enterprises Which results in the creation of many quasi-autonomous subsidiaries eligible for privatization or partnership. On the other hand, the process of privatization (total or partial) reduces a number of public SMEs that switch to "private" status [9]. These reasons explain why the total number of public SMEs 
according to the official figures of the Ministry of Industry increased from 778 SMEs in 2004 to 874 SMEs in 2005, to 739 in 2006 and 666 in 2007 and to 438 in 2016[8] .

\section{Methodology}

\subsection{Briefing Meeting}

Briefing meetings marking the launch of the mission in the presence of the manager of the company, and his Principal Assistant on the presentation of the SME, the strategy of the manager in the short and medium term and the objectives targeted through our action. Followed by weekly meetings aimed at collecting and stating the content and objectives of each intervention.

\subsection{Visit the Facilities}

Physical observations at the site were made through frequent visits to manufacturing sites, storage areas and the laboratory.

\subsection{In-Depth Individual Interview}

The present study was carried out mainly through in - depth interviews with the manager and managers of the various structures and through the consultation of the existing documentation and the registration forms and a consultation of the whole managerial documentary system of the "In particular the operational procedures for quality management. These discussions enabled us to see the deliverables of the upgrade actions and to appreciate their application by the manufacturer.

\section{Observations, Findings and Discussions}

\section{Description of the Company}

The company involved in this study specializes in the processing and marketing of meat and poultry. The Company started its activities in 1982 in a first site in the south west of Algiers with an SNC status. Since 1999, the status of the company has changed to an LLC divided into six shareholders (Brothers). A recapitalization was carried out in 2006, which is how the SME's share capital increased from 600 KDA to 35,000 KDA. Currently, and since 1999, the company is located in the El Alia business area, Bab Ezzouar. The company started up in the MEDA program during the second half of 2005.

\subsection{Organization of the SARL}

In interviewing the manager and managers, we found that the majority of the production staff can be assigned several tasks and can be asked to perform other tasks, as specified in the employment contracts signed by the agents (versatility). The company employs thirty three agents. 
Table 1: Number of employees

(Internal source of the company, 2009)

\begin{tabular}{llll}
\hline CATEGORY & FRAME & MAITRISE & EXECUTION \\
\hline Commercial & 1 & 3 & 0 \\
Production & 3 & 4 & 18 \\
Administration & 2 & 0 & 2 \\
\hline
\end{tabular}

\subsubsection{Human Resources Management}

Staff activity consists of updating staff administrative files and monitoring and clearance of files with external agencies. The person responsible for the personal service is responsible for the following tasks: Declaration CNAS, IRG (Taxes), Payroll and payroll, Maintenance of regulatory registers y Services, administrative records (follow-up leave, work certificates, medical follow-up (periodic visits, illnesses, accidents at work)). Through our various interviews, it turns out that the company suffers from remarkable mobility (significant turnover). Staff costs for the year 2008 show a $45 \%$ positive trend compared to 2005 . This change is mainly due to the impact of the organization's implementation and its reinforcement by Capacities capable of carrying out the upgrading operation and the workwear endowment of the collective production and support.

\subsubsection{Accounting Management}

The company has at its headquarters an accounting department responsible for entering accounting records, analyzing the accounts and the financial situation. All such management shall be audited at the end of each accounting period by an approved external audit office, which shall draw up and submit its special report relating to the audit of the accounts for the year ended at the general meeting of shareholders. On this occasion, the manager draws up and submits his own moral and management report for the year ended, as specified in the company's articles of association. Since the organizational upgrade action, Sarl has undergone a radical change, and has made it possible to set up a management and accounting system formalized in accordance with the good practices of accounting and administrative management in accordance with the provisions Regulations relating to the status of an SAR.

I) Purchasing Component

All procurement operations (raw materials, packaging, equipment and other) since launching, negotiation, formalization by written and sometimes verbal purchase order as well as supplier regulations, are carried out mainly by the manager and with less frequency By the shareholders. In other words, the decision of the purchase act is centralized at the shareholder level. As for imports, customs clearance operations are carried out by a freight forwarder.

\section{II) Sales Component}

From 2006 to 2008, the company acquired adequate means to ensure delivery via shareholders, which are organized by sector (Center, East, West), in addition to customers who take their goods to the factory. The company has adapted refrigerated transport facilities dressed in the whole range produced and marketed: 6 vans $(1200 \mathrm{~kg})$ and 3 vans $(3200 \mathrm{~kg})$. Indeed, sales are distributed by sector between the shareholder brothers and a member of their family. The 
average monthly distribution of products is 25 tons / month. The turnover in 2008 amounted to $31,000 \mathrm{KDA}$, of which $70 \%$ (only for the cachir product) and 30\% (for the pâté product and others). According to our calculations, the latter shows a negative trend of $18 \%$ compared to the turnover achieved the previous year. This regression is mainly due to the unavailability in sufficient quantity and quality of the range packaged in divisional packaging, this being the fact of the existence of an inadequate equipment often broken down. Below, we broke down sales for better analysis:

A) Breakdown of total sales by recipients

According to the information provided by the company, sales are broken down as follows:

Table 2: Breakdown of total sales by recipients

\begin{tabular}{llll}
\hline & In millions of Algerian Dinars (DA) \\
\hline Désignation & Grossistes Distributeurs & $\begin{array}{l}\text { Restaurants et } \\
\text { collectivités }\end{array}$ & Divers \\
\hline Cachir & 33,74 & 13,12 & 1,49 \\
Patés & 15,34 & 2,50 & 1,70 \\
Divers & 2,04 & 0,00 & 1,07 \\
\hline
\end{tabular}

(Based on company data, 2009)

The company is not concerned with direct sales (details), except for the company's staff. The main customers are the three brothers shareholders who distribute:

(customer 01: $15000 \mathrm{KDA}$, customer 02: $5000 \mathrm{KDA}$ and customer 03: 2,500 KDA). The company has tied loyalty to its customers, which means that they are essentially the same from one year to the next: wholesalers and distributors (80\%), restaurants and communities (17\%) And miscellaneous (3\%). Sales are formalized through the delivery slips and invoices, the statistical data of which are regularly taken over by the accountant who ensures the input and the drawing up of their declaration at the level of the external services concerned (taxes). Contact with customers is mainly through oral communication, through meetings or by telephone. The statistical information by product category, by customer, by geographical area, is available but not sufficiently dispersed to allow us to know the areas occupied by the SARL. In the absence of a marketing department, the company has a quality image recognized in the Algerian market through its organoleptic qualities. In recognition of this quality, some customers are loyal to the brand of the product, especially hide it. Trade policy is based on this image, which is spread word of mouth among potential buyers. The company often participates in fairs as a salesman. The company, conscious of its strategy of gradually occupying the market, considered it necessary to accompany its product by advertising media. Thus, it began to implement, in a first phase, the design of posters, leaflets and brochures. Visual audio advertising requiring the mobilization of a very large envelope will be considered in a second stage.

B) Estimated market share

In the absence of a nationally structured professional organization capable of collecting data and compiling statistics for the meat processing industry, the company does not carry out market research and therefore does not have objective references On its position on the Algerian market. It is impossible for the company to situate itself in relation to the whole of the activity. Especially since this market is making considerable progress in the production of these products, 
by increasing the number of manufacturers and expanding the range of products on display. Given the lack of documents stemming from a specific official survey enabling rational quantification in the meat sector in Algeria and In order to complement our work of estimating market share to locate the company. We found it important to carry out a survey of wholesalers. The market share in Algeria is around 15\%, of which 5\% is in the Central region. In order to gain a foothold in the market, the company has embarked on a strategic approach to the development and diversification of its range of access mainly to "rosettes" divisional packaging to increase the consumption of its product to households with Low purchasing power.

\section{C) Competition data}

The company does not have documents or data tracked and recorded on the competition. Given the general context of the Algerian market, in which the relationship plays an essential role, the manager and his sales representatives, through their regular business contacts, have a fairly precise idea of competition, both in terms of product availability and price. The estimates made in our study place the company in fourth place compared to the most serious competitors. The main competitors are: Bellat, Amour, Nour followed by From, CK Fleisch, Isla delice, Bahdja. It should be noted that the market situation of the sector presents an imbalance, following the nonrespect of the commercial rules by certain competitors. The finished products are marketed by the shareholders. It is the manager, in conjunction with the shareholders, who set the selling prices based on their acute knowledge of the market.

\subsubsection{The Production}

The current capacity of production varies from 2.5 to 3 tons / day, the production staff staff is 25 people including 3 executives, organized in a team and a half for a global time frame of 12 hours. The company manufactures a varied and diversified range of 45 products distributed over 12 families, each packaged in divisional packages ranging from $200 \mathrm{~g}$ to $2 \mathrm{~kg}$. Production in 2008 showed a decrease of around $16 \%$ compared to the previous year, due to irregularities and frequent disturbances Supply of production equipment, raw materials and quality packaging. On the other hand, the almost total unavailability of equipment intended for the production of the range in small packaging, which is still in high demand by potential customers specializing in mass retailing. In this study, we estimated the total cost of production per day as presented below:

Table 3: Estimated total production cost per day

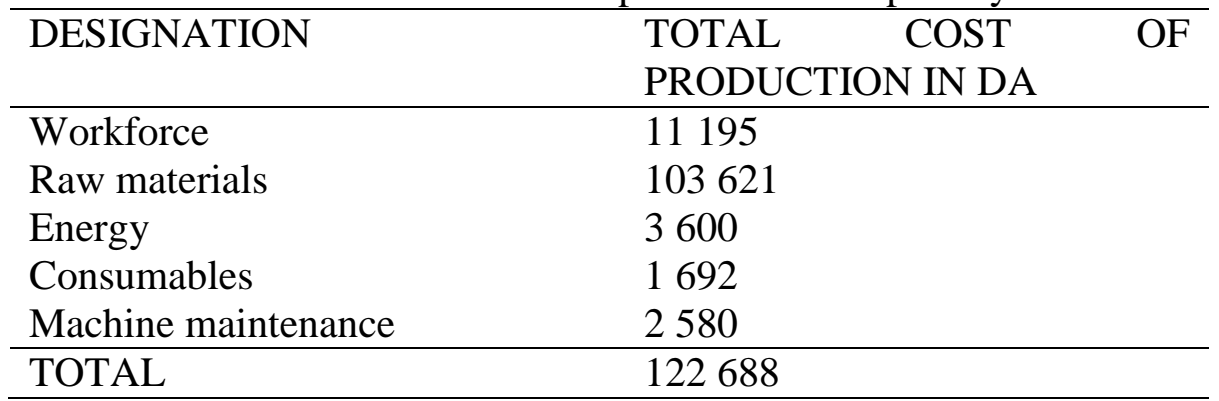

(Based on company data, 2009) 
It should be noted that the regular intervention following the frequent breakdowns recorded in the existing polyclip, requiring a supply of imported replacement parts for an equivalent value of about 1.6 million dinars for the rehabilitation of production equipment. The unit has a fleet of 19 plants, constituting a single production line, which does not limit its flexibility in the event of breakdowns. The production equipment is semi-automated. The current production can be doubled by the fact that the company has already implemented an investment plan for the optimization of the production tool. Investments made during the 2008 fiscal year as part of the upgrade of the company show an increase of $14 \%$ compared to investments made in 2007 . The company operates a production site of 2,600 m2, Located in the zone of activity in Bab Ezzouar, and also has an area adjoining the production unit, which can be used in the event of expansion or development of the current site. The cost of production is stable and allows sufficient margins to be invested. There is no standard or ratio on the profession as a standard.

\subsubsection{Quality Management and Laboratory Analysis}

The company has a laboratory that performs microbiological analyzes internally and exploits the microbiological analyzes of the laboratories providing the services. Indeed, in addition to the microbiological analyzes carried out internally, Sarl is in contact with other laboratories for conformity confirmation analyzes as an example. The Physico-chemistry part is provided by the Institut Pasteur. While quality management through daily quality control operations, and monitoring of manufacturing parameters, and compliance with good hygienic manufacturing practices as well as execution of the cleaning and disinfection plan.

\subsubsection{Sub-Contracted Activities}

We note that the activities of auditing, treatment of litigious files and legal advice, quality analyzes (Laboratories providers (Pasteur Institute, private laboratories, and veterinary Laboratory), customs clearance operations, Medical follow-up (labor medicine), maintenance Equipment, verification of fire extinguishers are provided by subcontractors.

\section{Conclusion}

This study indicates that the current organization and management of this company and the level of risk taking absent does not allow them to remain profitable on the market. It is the same observation of some earlier work [10], [11]. The need to align with international standards of organization and management is essential to significantly improve their competitiveness in order to successfully transfer to a second generation company that will consolidate and guide its future development. Despite all the support policies implemented; Many SMEs have therefore decided to divest themselves completely as soon as they realize that, in the diagnostic phase, in the implementation phase of the action plan validated jointly with the EDPME experts, State is limited to $20 \%$ of the total amount of the operation. This company is rentier and not very innovative; Its family aspect favors mainly the traditional management, It is not favorable to the taking of the risks. Like the other SMEs, the informal sector plays an important part in its activity, whether in financing [12], production, marketing or supply. The managers' level of education is limited, which has a detrimental effect on the strategy pursued by the company and 
prevents the renewal of the forms of management of SMEs; The quality of goods [13] and services [10] produced by the majority of SMEs is lower than that of competing foreign products

\section{References}

[1] ASSALA K., 2006. "SMEs in Algeria: From Creation to Globalization" Communication in the International Symposium "Internationalization of SMEs and their Implications for Entrepreneurial Strategies", 25-26 October 2006, Haute School of Management (HEG) Friborg, Switzerland.

[2] DAOUD S., 2006. "Development of small and medium-sized enterprises in Algeria: policies and obstacles", communication at the international symposium on "Globalization, institutions and productive systems in the Maghreb" 22 and 23 June 2006, Hammamet, Tunisia.

[3] Ministry of Small and Medium Enterprise and Handicrafts. Bulletin No. 17, December 2009.

[4] RAHMANI T., P. SANMARCO and TABARD S., 2006. "How can we effectively support the creation and growth of SMEs?". Seminar on Financial and Technical Support for Entrepreneurship Development, 11-14 December 2006, Tunis, Tunisia.

[5] Malmberg A., Maskell P., 2006. "Localized learning revisited", In Growth and Change Knowledge: What is at stake for Algeria in the context of globalization. Europeen University edition. (EUE), ISBN 978-3-8417-3879-0. Sarrebruck, Allemagne.

[6] Report of the International Monetary Fund (IMF) on Algeria, 2017. Available online at: http://www.imf.org/en/news/articles/2017/03/20/pr1790-algeria-imf-staff-completes-2017-articleiv-mission (Last accessed on 21/03/2017) [7] Ministry of Small and Medium Enterprise and Handicraft, 2007. Information Bulletin No. 12, indicators of the year 2009.

[7] Statistical Information Bulletin, Ministry of Industry and Mining; 2016, No. 29. Available online at http://www.mdipi.gov.dz/?Bulletin-de-veille-statistique (Last accessed on 02/01/2017).

[8] MIMOUNE L., KHELADI M., 2006. «Partenariat Algérie- Union européenne et mise à niveau des entreprises algériennes». Colloque international «Economie Méditerranée Monde Arabe; Le Partenariat euro-méditerranéen : Construction régionale ou dilution dans la mondialisation?», 26 et 27 mai 2006 Université Galatasaray, Istanbul, Turquie.

[9] GILLET A., 2003. «Les entrepreneurs algériens de petites entreprises: un groupe hétérogène entre logiques domestiques et logique économique capitaliste» - Document de Travail 16- GriotCnam.

[10] MELBOUCI L., 2004. "The growth of Algerian SMEs through resource theory", 7th International Francophone Congress on Entrepreneurship and SMEs - IFEPME, 2004.

[11] NAIT MERZOUG ML., 2006. "Financing Small and Medium-Sized Enterprises in Algeria", International Symposium: SMEs in Arab Countries, 17-18 April 2006, Hassiba BenBouali University, Chlef.

[12] OUABDESSELAM L. and SAYAD A., 2014 Implementation of the HACCP system in an Agrifood company: Case study (Charcuterie), Europeen University edition. Sarrebruck. (EUE), ISBN 978-3-8417-3879-0. Sarrebruck, Allemagne.

*Corresponding author.

E-mail address: ouabdesselam.lyes@yahoo.com 